\section{Cureus}

\title{
Case Report: Rasmussen's Encephalitis Treated Successfully with Rituximab
}

\author{
Juliana Lockman ${ }^{1}$, Scheherazade Le ${ }^{2}$, Robert S. Fisher ${ }^{3}$, Kenneth Laxer ${ }^{4}$ \\ 1. The Oregon Clinic, Legacy Health 2. Stanford Comprehensive Epilepsy Center, Stanford University 3. \\ Stanford University School of Medicine 4. California Pacific Medical Center
}

$\square$ Corresponding author: Scheherazade Le, schele@stanford.edu

Disclosures can be found in Additional Information at the end of the article

\section{Abstract}

Rasmussen's encephalitis (RE), or chronic focal encephalitis, is a progressive neurologic condition consisting of cognitive regression, hemiparesis, and intractable epilepsy. While the etiology is unknown, evidence supports an autoimmune basis. Although steroids, plasmapheresis, and intravenous immunoglobulin (IVIg) may afford limited benefit, standard of care for pediatric cases typically involves hemispherectomy. In this report, we present a case of adult-onset Rasmussen's encephalitis with intractable epilepsy, ultimately responsive to a rituximab (Rituxan ${ }^{\circledR}$ ) anti-B lymphocyte treatment protocol.

Categories: Internal Medicine, Neurology

Keywords: chronic focal encephalitis, epilepsia partialis continua, immune therapy, rasmussen's encephalitis, rituximab

\section{Introduction}

Rasmussen's encephalitis (RE) or chronic focal encephalitis is a progressive neurologic disease characterized by cognitive regression, hemiparesis, and focal onset epilepsy [1]. Approximately $85 \%$ of affected individuals are 10 years old or younger [2]. Epilepsy can become intractable and is frequently heralded by epilepsia partialis continua progressing to other seizure types. Neuroimaging studies show progressive unilateral hemispheric atrophy [3]. Although no etiology has been identified, brain specimens often demonstrate chronic inflammatory changes [4]. Serum studies may reveal antibodies to neuronal elements including glutamate receptor type 3 (GluR3), however, this is not a specific marker of RE [5]. Surgical intervention in the form of hemispherectomy is the most definitive option to halt progression of the disease, although it is often not a viable option in dominant hemisphere or adult onset cases [6]. Here, we discuss a case of RE that was partially responsive to rituximab.

Received 05/22/2013 Review began 05/23/2013 Published 08/23/2013

\section{(๑) Copyright 2013}

Lockman et al. This is an open access article distributed under the terms of the Creative Commons Attribution License CC-BY 3.0., which permits unrestricted use, distribution, and reproduction in any medium, provided the original author and source are credited.

\section{Case Presentation}

A 25-year-old woman was referred for seizures refractory to medical management. Events began four years prior to referral and consisted of rhythmical twitching of the right hand, which spread to involve the right face or leg. Consciousness was preserved with the events. They lasted an average of one minute and would stop and restart, eventually occurring up to multiple times in an hour. The seizures occurred during wakefulness and sleep. The patient experienced intermittent paresthesias in her right hand and leg, independent of her finger twitching.

Prior studies included MRI and EEG, both of which were reported to be unremarkable. The 
patient was taking phenobarbital and levetiracetam at presentation to our hospital. Her exam showed normal language skills but an irregular, moderate-to-high amplitude twitching movements of her right hand at times with extension of her hand or individual fingers. She had variable weakness in the right arm, more so after vigorous or prolonged episodes of twitching. Rapid alternating movements with the right hand were slow and clumsy compared to the left hand.

Video-EEG monitoring recorded several clusters of right arm jerking with occasional spread to the right leg. The EEG revealed frequent runs of periodic lateralized epileptiform discharges (PLEDs) either at the vertex or broadly distributed over the left hemisphere, associated with time-locked right shoulder and arm myoclonus. Baseline EEG demonstrated nearly continuous polymorphic theta and delta slowing over the left hemisphere. A presumptive diagnosis of RE was made. Unsuccessful medication trials included clonazepam, topiramate, zonisamide, oxcarbazepine, levetiracetam, pregabalin, gabapentin, and phenobarbital.

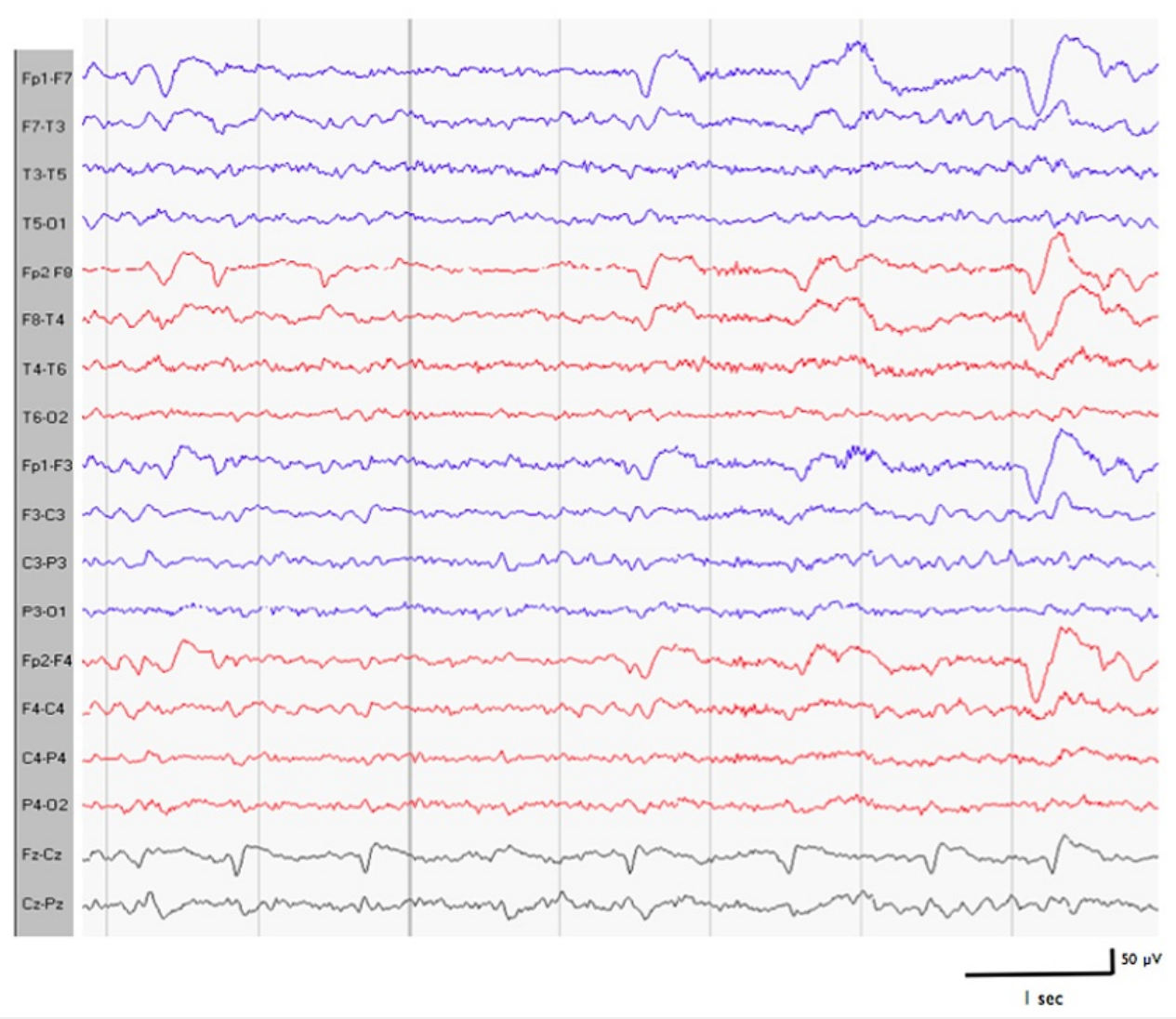

\section{FIGURE 1: EEG showing periodic epileptiform discharges (PLEDs) at the vertex ( $\mathrm{Cz}$ electrode) associated with time- locked right shoulder and arm myoclonus}

She underwent an HMPAO-SPECT injection eight minutes after a series of arm jerks and 10 minutes before the reappearance of focal seizures. The study showed decreased tracer uptake in the left frontal, temporal and parietal lobes. Routine CSF studies and cytology were normal.

The following laboratory studies were normal: CBC, basic metabolic panel, liver panel, ANA, ESR, CRP, prothrombin time and partial thromboplastin time, ACE, RPR, anti-thyroid peroxidase, TSH, homocysteine, anti-DNA Ab, antiphospholipid antibodies, serum IgG, IgA, 


\section{Cureus}

and IgM levels, Mayo Clinic paraneoplastic autoantibody panel [ANNA-1 (Hu) Ab, ANNA-2 (Ri) Ab, ANNA-3 Ab, Purkinje Cell 1 (Yo) Ab, Purkinje Cell 2 Ab, Purkinje Cell Trotter Ab, Amphiphysin Ab, CRMP-5 IgG, Striated Muscle Ab, Ca Channel Binding P/Q Ab, Ca Channel Binding N Ab, ACHR Binding Ab, and ACHR Ganglionic Neuronal Ab], and ENA antibodies (including SCL-70, SS-A Ro, and SS-B La). Rheumatoid factor was slightly elevated at 23.

Antibodies directed against voltage-gated potassium channels (VGKC) of the KV1.2-KV1.4 type were positive in the patient's serum. Two days after drawing blood for antibody studies, she received the first of three courses of IVIg, 2 grams divided over five days. Slight reduction in seizure frequency and clinical spread occurred over the week after the first course of IVIg, but subsequent courses produced little or no benefit.

The patient was subsequently treated with plasma exchange (PEX), five plasma volumes exchanged with albumin and electrolyte correction over 10 days. PEX produced transient reduction in seizures, each lasting one to three months. Over time, the motor function in her right arm worsened and seizures spread more often to the right leg and face. She experienced a decline in her ability to do activities, such as dancing, painting, and writing. Repeat MRI, completed ten months after presentation, showed volume loss in the left frontoparietal and temporal lobes.

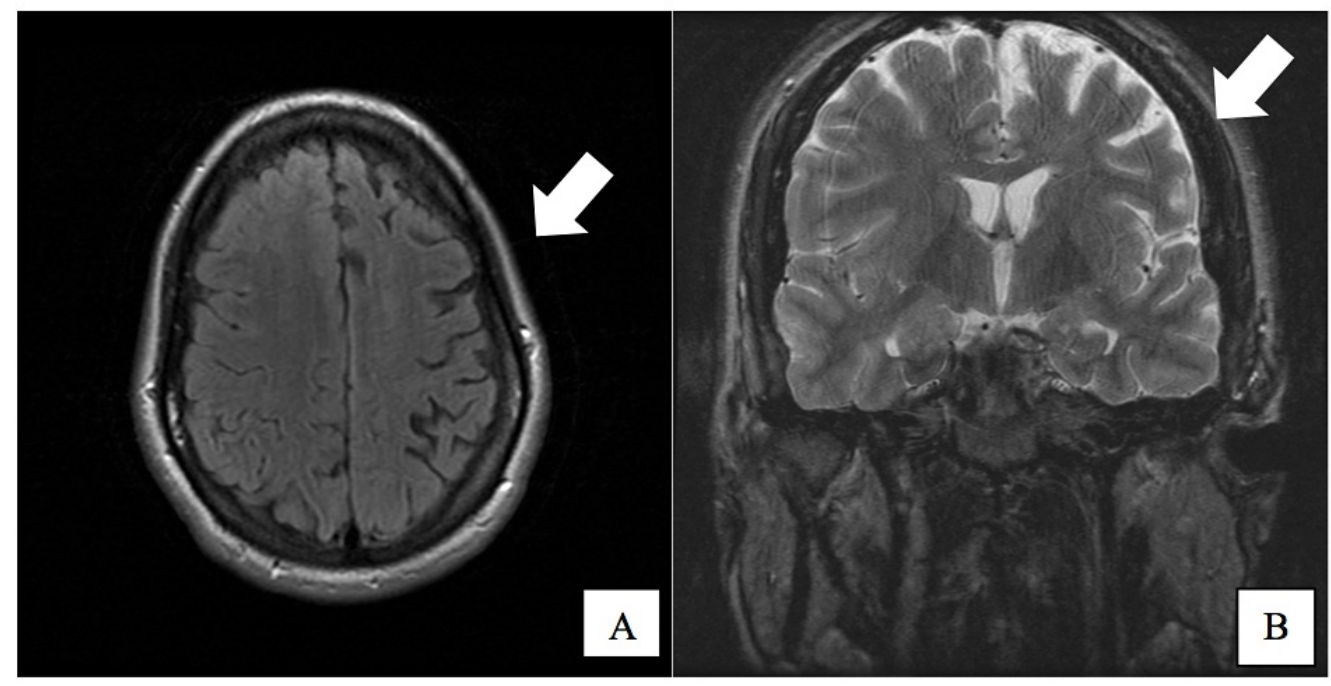

\section{FIGURE 2: MRI of the brain ten months after referral}

MRI of the brain ten months after referral. (A) axial fluid attenuated inversion recovery (FLAIR) and (B) coronal T2-weighted image showing atrophy in the left frontoparietal and temporal lobes.

In May 2008, almost two years after the patient was referred to the Epilepsy Center, she entered a rituximab (Rituxan ${ }^{\circledR}$ ) monoclonal anti-CD20 B cell antibody treatment protocol [7]. Per protocol, she received four consecutive weekly infusions of rituximab at $375 \mathrm{mg} / \mathrm{m} 2$ for a total of one course. She underwent a three day course of PEX approximately two months following rituximab (RTX) treatment.

Immediately following RTX, she became seizure-free. One year follow-up revealed substantial improvement in seizure frequency and right hand dexterity. She was able to regain her ability to do activities, such as painting, dancing, and writing. She experienced only a daily twitch in 
the right pinky finger. After initial RTX therapy in May 2008 and subsequent PEX two months after, she went without significant seizure activity or need for PEX for 17 months. Follow-up assay of the VGKC KV1.2-KV1.4 antibody showed a negative titer.

Beginning in November 2009, she had a gradual recurrence of focal seizures from three times per week to multiple episodes per day occasionally requiring repeat PEX. By January of 2011, right arm focal seizures recurred at a frequency of three to 10 per day. A second course of Rituxan ${ }^{\circledR}$ (kindly provided on a compassionate basis by Genentech, Inc.) was given, with intravenous dose rounded to $800 \mathrm{mg}(375 \mathrm{mg} / \mathrm{m} 2$ at 5'10", $110 \mathrm{~kg}$, body surface area $2.3 \mathrm{~m} 2)$ for three weekly courses beginning 6/20/11. By two weeks after completion of the second course, seizures improved to 0 to three per day for next four months, then resumed in October 2011 at 10 per day. She subsequently received two treatments with PEX, each time with several months reduction to 0 to three simple partial seizures per day. Interval neuroimaging in 2012 continued to show slight progressive left hemispheric atrophy.

\section{Discussion}

Our patient demonstrated sustained improvement in simple partial seizures and coordination of her right hand after treatment with RTX. IVIg previously failed to produce improvement and PEX repeatedly produced improvement for only a month or two. A key question is whether the improvement was attributable to the RTX. This cannot be ascertained in an uncontrolled case report, but it is notable that she had no such improvement for the six prior years and improvement occurred again after a second RTX course. Improvement lasted approximately 1.5 years after the first treatment and four months after the second; less sustained improvement after the second RTX course could be attributable to the natural progression of the underlying disease process.

An investigation of RTX to treat chronic focal encephalitis was conducted by Laxer and colleagues as a multi-center, open-label, uncontrolled pilot study of nine patients [7]. The present patient was included among this group (for the first course). A course of treatment consisted of weekly IV infusions of RTX for a total of four doses (375 mg/m2). Patients received either one or two courses (separated by six months). At follow-up of three to 22 months, eight of nine patients showed good response in terms of seizure frequency (50-100\% decrease) and severity as well as cognitive and/or motor functioning. There was no evidence for toxicity or progression of disease in the trial.

Another previous case report of RTX for Rasmussen's encephalitis was published by Thilo and coworkers [8]. Investigators described a case of a 20-year-old woman with diagnosis of the syndrome seven years prior, presenting with refractory epilepsia partialis continua. In conjunction with other therapies, a trial of IV RTX at $375 \mathrm{mg} / \mathrm{m} 2$ once per week for four weeks was associated with depletion of $C D+19$ B cells and seizure freedom for six months.

Evidence supports an autoimmune basis for RE. Early in the disease, signs of immunopathology in resected brain tissue include perivascular cuffing, lymphocyte infiltration, and activated microglia in the setting of neuronal loss [1]. As the disease progresses, inflammatory features are superseded by more extensive neuronal loss with gliosis and necrosis [9]. Further clues to an immune-mediated mechanism for neuronal destruction include the demonstration of Glu3 receptor antibodies and involvement of B- and cytotoxic T-cells [10]. These findings have prompted the use of immunosuppression and modulation therapies, such as steroids, PEX, and IVIg [11-12]. Such therapeutic modalities have shown positive effect on seizure frequency for some patients in the short-term. Long-term outcomes are less clear [13-14]; however, Kupila and colleagues have reported a case of late onset biopsy proven RE who has been seizure-free with a normal neurologic exam for at least three years through a combination of anti-epileptic medications, steroids and monthly IVIg [12]. 
Rituximab is believed to promote an antibody and complement-dependent cytotoxicity of lymphoid cells expressing CD20 antigen, resulting in the clearance of B cells from blood, lymph nodes and marrow [15]. It has also been studied in a variety of non-malignant autoimmune disorders where B cells and autoantibodies appear to play a role in pathophysiology. Rituximab has FDA approved indications in rheumatoid arthritis, non-Hodgkin lymphoma and chronic lymphocytic leukemia, and it additionally has been reported to relieve signs and symptoms of lupus, immune thrombocytopenia, autoimmune anemia, autoimmune neuropathy, neuromyelitis optica, myasthenia gravis, and paraneoplastic disorders, such as anti-NMDA receptor limbic encephalitis or opsoclonus-myoclonus syndrome.

We hypothesize that RTX therapy, in our case, depleted the clone of lymphoid B cells producing the potassium channel antibody found in our patient. However, we also are aware that VGKC antibodies may be found in up to $11 \%$ of patients with epilepsy [16], and the antibody identified in our patient may not be the cause of her epilepsy. Benefit of RTX was temporary in our patient, but more lasting than effects of steroids, IVIg or plasmapheresis. RTX may also be less invasive and more convenient than plasmapheresis. The response of this patient to RTX supports development of a clinical trial of RTX as a treatment for Rasmussen's encephalitis [17].

\section{Conclusions}

N/A

\section{Additional Information \\ Disclosures}

Human subjects: Consent was obtained by all participants in this study. Conflicts of interest: In compliance with the ICMJE uniform disclosure form, all authors declare the following:

Payment/services info: All authors have declared that no financial support was received from any organization for the submitted work. Financial relationships: All authors have declared that they have no financial relationships at present or within the previous three years with any organizations that might have an interest in the submitted work. Other relationships: All authors have declared that there are no other relationships or activities that could appear to have influenced the submitted work.

\section{References}

1. Rasmussen T, Olszewski J, Lloydsmith D: Focal seizures due to chronic localized encephalitis . Neurology. 1958, 8:435-45.

2. Oguni $\mathrm{H}$, Andermann F, Rasmussen $\mathrm{T}$ : The natural history of the syndrome of chronic encephalitis and epilepsy: A study of the MNI series of 48 cases. Neurology. 1989, 39:155.

3. Bien CG, Urbach H, Deckert M, Schramm J, Wiestler OD, Lassmann H, Elger CE: Diagnosis and staging of Rasmussen's encephalitis by serial MRI and histopathology. Neurology. 2002, 58:250-257.

4. Deb P, Sharma MC, Gaikwad S, Tripathi M, Chandra PS, Jain S, Sarkar C: Neuropathological spectrum of Rasmussen encephalitis. Neurol India. 2005, 53:156-60.

5. Granata T: Rasmussen's syndrome. Neurol Sci. 2003, 24:S239-S243.

6. McClelland III S, Maxwell RE: Hemispherectomy for Intractable Epilepsy in Adults: The First Reported Series. Ann Neurol . 2007, 61:372-376.

7. Laxer KD, Wilfong A, Morris GL, Andermann F: Pilot Study of Rituximab to Treat Chronic Focal Encephalitis. American Epilepsy Society Annual Conference. Genentech, South San Francisco; 2008. Abstract 1.277:

8. Thilo B, Stingele R, Knudsen K, Boor R, Bien C: A case of Rasmussen encephalitis treated with rituximab. Nat. Rev. Neurol. 2009, 5:458-62.

9. Robitaille Y: Neuropathologic aspects of chronic encephalitis. Chronic encephalitis and epilepsy: Rasmussen's syndrome, Illustrated edition. Andermann F (ed): Butterworth- 


\section{Cureus}

Heinemann, Boston; 1991. 89-110.

10. Rogers SW, Andrews PI, Gahring LC, Whisenand T, Cauley K, Crain B, Hughes TE, Heinemann SF, McNamara JO: Autoantibodies to glutamate receptor GluR3 in Rasmussen's encephalitis . Science. 1994, 265:648-651.

11. Granata T, Fusco L, Gobbi G, Freri E, Ragona F, Broggi G, Mantegazza R, Giordano L, Villani F, Capovilla G, Vigevano F, Bernardina BD, Spreafico R, Antozzi C: Experience with immunomodulatory treatments in Rasmussen's encephalitis. Neurology. 2003, 61:1807-10.

12. Kupila L, Jutila L, Immonen A, Vanninen R, Mervaala E, Pateau A, Luostarinen L, Kalviainen R: Late-onset Rasmussen's encephalitis and long-term remission. Epileptic Disord. 2011, 13:88-91.

13. Hart YM, Cortez M, Andermann F, Hwang P, Fish DR, Dulac O, Silver K, Fejerman N, Cross H, Sherwin A: Medical treatment of Rasmussen's syndrome (chronic encephalitis and epilepsy): effect of high-dose steroids or immunoglobulins in 19 patients. Neurology. 1994, 44:1030-6.

14. Andrews PI, Dichter MA, Berkovic SF, Newton MR, McNamara JO: Plasmapheresis in Rasmussen's encephalitis. Neurology. 1996, 46:242-246.

15. Taylor RP, Lindorfer MA: Immunotherapeutic mechanisms of anti-CD20 monoclonal antibodies. Curr. Opin. Immunol. 2008, 20:444-9.

16. McKnight K, Jiang Y, Hart Y, Cavey A, Wroe S, Blank M, Shoenfeld Y, Vincent A, Palace J, Lang B: Serum antibodies in epilepsy and seizure-associated disorders . Neurology. 2005, 65:1730-6.

17. Schmalbach B: New Hope for Rasmussen Encephalitis . Discov Med. 2009, 8:130-2. 